\section{Discussion}

Successful bone-marrow transplantation from an unrelated donor has been reported for treatment of acute myeloid leukaemia in remission. ${ }^{7}$ It has not been reported before in the treatment of severe aplastic anaemia with evidence of sustained engraftment, though unsuccessful attempts have been made. ${ }^{8} 9$ Both the patients reported on here received many blood transfusions. Multiple blood transfusions are associated with an increased risk of graft rejection in aplastic anaemia, ${ }^{10}$ though possibly the use of cyclosporin A permitted engraftment in our patients despite this problem. ${ }^{11}$ Graft-versus-host disease occurred in both patients but in each case the acute episodes responded to treatment. The man had chronic graft-versus-host disease of the skin, which seemed to respond to prednisone and azathioprine. Both patients had stormy courses after grafting. Some of the infectious complications in the woman may have been related to the delay in bone-marrow transplantation since she had proved septicaemia before starting. Herpes zoster infections are common after grafting. ${ }^{12}$ The hepatic and renal failure in the man was probably related to drug treatment, including intravenous cyclosporin $\mathrm{A}$ and antibiotics. ${ }^{13}$ These patients show, however, that unrelated volunteers may donate marrow successfully for the treatment of severe aplastic anaemia. There are many logistical problems in this procedure that cause delay in identifying suitable donors, and the ethical questions raised in giving an anaesthetic to a healthy volunteer need wider discussion. The use of mismatched family donors has not yet been explored in aplastic anaemia, mainly because the increased problems encountered using these donors in leukaemic patients ${ }^{14}$ may prove difficult to overcome in patients with aplastic anaemia, who are generally more ill. Despite the problems encountered in the management of these two patients, bone-marrow transplantation from unrelated, histocompatible donors does offer a chance of cure in severe aplastic anaemia.

\section{References}

${ }^{1}$ Camitta BM, Thomas ED, Nathan DG, et al. Severe aplastic anaemia: a prospective study of the effect of early marrow transplantation on acute mortality. Blood 1976;48:64-70.

2 UCLA Bone Marrow Transplant Team. Bone marrow transplantation in severe aplastic anaemia. Lancet 1976;ii:921-3.

${ }^{3}$ Speck B, Gratwohl A, Nissen C, et al. Treatment of severe aplastic anaemia with antilymphocyte globulin or bone marrow transplantation. $\mathrm{Br} \mathrm{Med} \mathcal{F}$ $1981 ; 282: 860-3$

${ }^{4}$ Bacigalupo A, Podesta M, Van Lint MT, et al. Severe aplastic anaemia: correlation of in vitro tests with clinical response to immunosuppression in 20 patients. Br $\mathcal{F}$ Haematol $1981 ; 47: 423-42$.

${ }^{5}$ Wooley P, Griffin J, Panayi GS, Batchelor JR, Welsh KI, Gibson TJ. HLA-DR antigens and toxic reaction to sodium aurothiomalate and D-penicillamine in patients with rheumatoid arthritis. $N$ Engl $\mathcal{F}$ Med 1980;303:300-2.

6 Sengar DPS, Terasaki PI. A semimicro mixed leukocyte culture test. Transplantation 1971;11:260-7.

${ }^{7}$ Hansen JA, Clift RA, Thomas ED, Buckner CD, Storb R, Giblett ER. Transplantation of marrow from an unrelated donor to a patient with acute leukaemia. $N$ Engl f Med 1980;303:565-7.

${ }^{8}$ Speck B, Zwaan FE, van Rood JJ, Eernisse JG. Allogeneic bone marrow transplantation in a patient with aplastic anaemia using a phenotypically HL-A-identical unrelated donor. Transplantation 1973;16:24-8.

${ }^{9}$ Lohrmann HP, Dietrich M, Goldmann SF, et al. Bone marrow transplantation for aplastic anaemia from a HL-A and MLC-identical unrelated donor. Blut $1975 ; 31: 347-54$

10 Storb R, Prentice RL, Thomas ED. Marrow transplantation for aplastic anaemia. Factors associated with rejection. $N$ Engl f Med 1977;296:61-6.

${ }^{11}$ Hows JM, Palmer S, Gordon-Smith EC. Use of cyclosporin A in allogeneic bone marrow transplantation for severe aplastic anaemia. Transplantation 1982;33:382-6.

12 Atkinson K, Meyers JD, Storb R, Prentice RL, Thomas ED. Varicellazoster virus infection after marrow transplantation for aplastic anaemia or leukaemia. Transplantation 1980;29:47-50.

${ }^{13}$ Powles RL, Morgenstern GR. Allogeneic bone marrow transplantation using mismatched family donors. In: White D, Powles $\mathrm{R}$, McMasters $\mathrm{P}$, Davis A. Proceedings of the international symposium on cyclosporin A. Amsterdam: Elsevier (in press).

${ }^{14}$ Hows JM, Palmer S, Want S, Dearden D, Gordon-Smith EC. Serum levels of cyclosporin $\mathrm{A}$ and nephrotoxicity in bone marrow transplant patients. Lancet 1981 ;ii:144-5.

(Accepted 6 August 1982)

\title{
Pyoderma gangrenosum associated with primary thrombocythaemia
}

\author{
PAUL SHEPHERD, KEITH LIDDELL
}

\begin{abstract}
Pyoderma gangrenosum is most commonly associated with inflammatory bowel disease and rheumatoid arthritis, but it has been associated with various haematological malignancies. A 54-year-old man with no history of bowel disease or arthritis presented with a leg ulcer, which healed after treatment. Results of bone marrow aspiration were compatible with primary thrombocythaemia. Seven weeks later there was pronounced recurrence of the ulceration and pyoderma gangrenosum was diagnosed.
\end{abstract}

District General Hospital, Eastbourne, East Sussex BN21 2UD PAUL SHEPHERD, MB, BS, house physician (now: general practitioner vocational trainee)

KEITH LIDDELL, MD, MRCP, consultant dermatologist
The appearance of pyoderma gangrenosum associated with blood disorders may differ from that associated with bowel and joint disease.

\section{Introduction}

Pyoderma gangrenosum has been rarely associated with various haematological malignancies. We report an association with primary thrombocythaemia.

\section{Case report}

A 54-year-old Caucasian man presented with a four-week history of increasing ulceration on the outer aspect of the left lower leg. There was no history of bowel disease, varicose veins, or arthritis, and peripheral pulses in the legs were strong. Results of investigations at this time were: haemoglobin $15 \cdot 1 \mathrm{~g} / \mathrm{dl}$, red cell count $6.68 \times 10^{12} / \mathrm{l}$, packed cell volume $0 \cdot 464$, white cell count $16.4 \times 10^{9} / 1$, and platelets $1210 \times 10^{9} / 1$; leucocyte alkaline phosphatase activity was normal. The 
results of bone marrow aspiration were compatible with primary thrombocythaemia. The ulcer healed successfully after treatment with oral flucloxacillin and local application of aureomycin cream. He was started on a course of busulphan for his blood disorder.

Seven weeks later there was a pronounced recurrence of the ulceration, now covering the entire outer aspect of the left lower leg. On examination the ulcer had a ragged undermined margin with a bluish tinge, and the edge resembled a collapsed bulla. The appearance was suggestive of pyoderma gangrenosum and biopsy confirmed this diagnosis. Rheumatoid factor was absent, serum protein concentrations and immunoglobulin electrophoresis were normal, and sigmoidoscopy (up to $18 \mathrm{~cm}$ ) showed no abnormality. He was given prednisolone $40 \mathrm{mg}$ daily, which produced a rapid improvement in the lesion in two weeks and complete healing in five. He now remains in good health without any medication.

\section{Discussion}

Pyoderma gangrenosum is most commonly associated with inflammatory bowel disease and rheumatoid arthritis, though it has been reported in association with various forms of leukaemia, $^{12}$ myelofibrosis, ${ }^{3}$ and polycythaemia rubra vera. ${ }^{45}$
Perry et $a l^{1}$ reported a more bullous variety of pyoderma gangrenosum associated with leukaemia, which accords with the appearance of the lesion in our patient. The appearance of pyoderma gangrenosum associated with blood disorders may differ from that associated with bowel and joint disease. We can find no confirmed reports of an association with primary thrombocythaemia.

\section{References}

1 Perry HO, Winkelmann RK. Bullous pyoderma gangrenosum and leukaemia. Arch Dermatol 1972;106:901-5.

2 Romane J. Pyoderma gangrenosum and myeloproliferative disorders. Arch Intern Med 1979;139:932-4.

3 Gopinath DK, Wolfe RD, Sabharwal K. Pyoderma gangrenosum with myelofibrosis. F Ky Med Assoc 1974;72:548-50,566.

4 Feuerman E, Potruch-Eisenkraft S. Pyoderma gangrenosum. Un cas de polycythaemie vraie. Bulletin de la Société Française de Dermatologie $\vec{\circ}$ et de Syphiligraphie 1971;78:260-1.

5 Feuerman E, Potruch-Eisenkraft $S$. The problem of pyoderma gangrenosum. Harefuah $1971 ; 80: 251-4$.

(Accepted 14 fuly 1982)

\title{
Chlorpropamide-alcohol flushing, aldehyde dehydrogenase activity, and diabetic complications
}

\author{
H ÖHLIN, P JERNTORP， B BERGSTRÖM， L-O ALMÉR
}

\begin{abstract}
Many diabetics who take chlorpropamide (a sulphonylurea compound) experience facial flushing after drinking even small amounts of alcohol. These flushers have a noticeably lower prevalence of late complications of diabetes (microangiopathy, macroangiopathy, and neuropathy) than non-flushers. This flush reaction is accompanied by increased blood acetaldehyde concentrations, suggesting an inhibition of aldehyde dehydrogenase activity. In the present study the activity of this enzyme in erythrocytes was assessed in the absence of chlorpropamide. Erythrocyte homogenates obtained from flushers and non-flushers were incubated with acetaldehyde and the rate of metabolism studied. Flushers eliminated acetaldehyde more slowly at a low range of concentrations $(0-30 \mu \mathrm{mol} / 1)$, suggesting a difference in aldehyde dehydrogenase activity. Further studies are needed to clarify the role of this enzyme in the pathogenesis of diabetic complications.
\end{abstract}

\section{Introduction}

For 25 years facial flushing after intake of small amounts of alcohol has been a well-known side effect of chlorpropamide medication, ${ }^{1}$ a sulphonylurea derivative used in the treatment

\footnotetext{
Department of Internal Medicine, University of Lund, Malmö General Hospital, Malmö, Sweden

H ÖHLIN, MD, registrar

P JERNTORP, MD, registrar

B BERGSTRÖM, MD, registrar

L-O ALMÉR, MD, lecturer
}

of type II diabetes (non-insulin-dependent or maturity-onset diabetes). The implications of the flush were not known until 1978, however, when Leslie and Pyke $^{2}$ reported that chlorpropamide-alcohol flushing was inherited as an autosomally dominant trait in type II diabetes. This was followed by reports of a lower prevalence of diabetic retinopathy, ${ }^{3}$ large-vessel disease, ${ }^{4}{ }^{5} \stackrel{2}{\overrightarrow{7}}$ peripheral neuropathy, ${ }^{5}$ and diabetic nephropathy ${ }^{6}$ in the flushers than in the non-flushers. The prevalence of chlorpropamide-alcohol flushing in type II diabetes has varied considerably at around $30 \%$.

Since the flush reaction seemed to be related to the pathogenesis of angiopathy, studies of its biochemical basis were warranted. We found that flushers had higher blood concentra- $\frac{5}{3}$ tions of acetaldehyde, the first metabolite of ethanol, than nonflushers during a chlorpropamide-alcohol challenge test. ${ }^{7}$ We $ᄋ$ also found higher concentrations of chlorpropamide in flushers $₹$ than in non-flushers, ${ }^{8}$ which accords with the fact that chlor- $\frac{\text { O }}{2}$ propamide-induced inhibition of aldehyde dehydrogenase leads $N$ to a rise in blood acetaldehyde concentrations. ${ }^{9}$ Barnett et $a l^{10} \rightarrow$ did not detect this difference in chlorpropamide concentrations between flushers and non-flushers, although they confirmed our finding that acetaldehyde concentrations were increased during $\mathcal{N}$ the flush. This discrepancy can be explained by the different $\omega$ size of the populations studied (105 subjects in our study ${ }^{8}$ and 21 in theirs ${ }^{10}$ ). Furthermore, we found a considerable overlap ${ }^{\circ}$ in serum chlorpropamide concentrations, whereas the difference $\stackrel{\mathbb{D}}{\mathcal{D}}$ in blood acetaldehyde concentrations was highly significant ${ }_{-}^{+}$ with a minimal overlap. Obviously other factors might be of $\frac{0}{0}$ importance. This prompted us to study the role of aldehyde $\frac{\vec{D}}{\mathbb{D}}$ dehydrogenase in diabetes.

Acetaldehyde is converted to acetate by aldehyde dehydro- $\stackrel{\mathbb{Q}}{\varrho}$ genase, which is distributed in various organs, the highest activity being found in the liver. ${ }^{11}$ Two major isoenzymes have 8 been isolated from mammalian livers; one is mitochondrial with? a low $\mathrm{K}_{\mathrm{m}}$ for aldehydes, the other is cytosolic with a high $\mathrm{K}_{\mathrm{m}}$ 